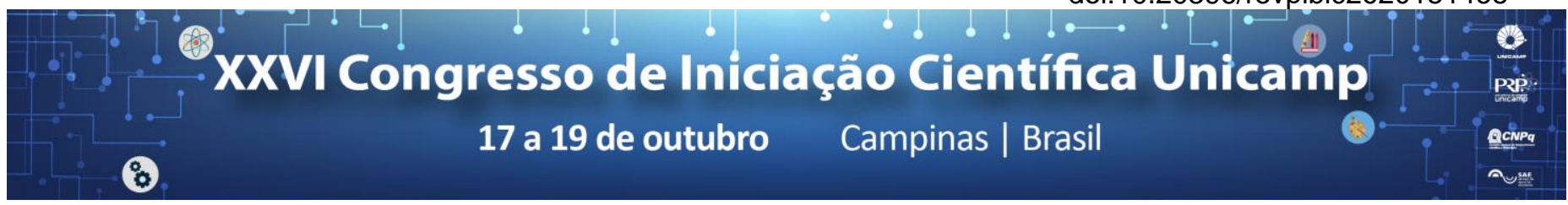

\title{
Avaliação da toxicidade in vivo de Melaleuca alternifolia
}

\author{
Bianca A. de O. Miglioranza*, Felipe C. Salles, Henrique B. Mendonça, Matheus V. T. da Silva, Vinícius dos S. \\ Petinate, José Francisco Höfling.
}

\section{Resumo}

As plantas medicinais há muito vêm sendo empregadas como terapêutica no tratamento de doenças, utilizando seus extratos, óleos e respectivos componentes bioativos. Dado o desenvolvimento de pesquisas científicas realizadas para a comprovação da atividade dessas plantas, visando à obtenção de novos fármacos, tem sido possível determinar o caráter empírico da utilização das plantas. Nesse contexto, Melaleuca spp., é uma das espécies mais citadas em estudos microbiológicos terapêuticos da literatura. Os resultados desses estudos, associado ao aumento de casos de resistência à antimicrobianos apresentadas por alguns microrganismos, evidencia a importância de trabalhos que visam a busca de novas alternativas de compostos antimicrobianos. No entanto, para aplicação clínica de tal substância é necessário estudos sobre sua toxicidade para sua possível aplicação clínica. Sendo assim, o objetivo do presente estudo foi avaliar a toxicidade do óleo essencial de Melaleuca alternifolia através da exposição de larvas de Galleria mellonella nas concentrações de 4 e $8 \mathrm{mg} / \mathrm{mL}$ do óleo. O óleo essencial de Melaleuca alernifolia não apresentou toxicidade sobre as larvas de Galleria mellonella.

\section{Palavras-chave:}

Melaleuca spp., Galleria Mellonella, toxicidade.

\section{Introdução}

O uso das plantas medicinais é uma prática milenar e descrita por praticamente todos os povos que se têm relatos e transmitido entre as gerações e é utilizado até hoje. Nos últimos anos o desenvolvimento de pesquisas em torno dessa temática tem auxiliado a comprovação de atividade dessas plantas visando à obtenção de novos compostos com propriedades terapêuticas (Cechinel Filho \& Yunes, 1998; Santos et al., 2009; Oliveira et al., 2007). Estudos com essa temática são de grande importância para a saúde pública uma vez que diversas espécies microbianas tem apresentado resistência à drogas antimicrobianas já existentes (Wynn et al., 1999). Sendo assim, o estudo preliminar da toxicidade desse óleo essencial para complementar estudos da atividade antimicrobiana são necessários para que derivados dessas plantas possam ser utilizadas com segurança como potenciais fontes para novos produtos farmacológicos.

\section{Resultados e Discussão}

A literatura relata que o óleo essencial de Melaleuca alternifolia possui reconhecidas propriedades antimicrobianas, podendo assim ser uma alternativa para o controle de patógenos, inclusive patógenos orais (Astani et al., 2010; Filoche et al., 2005; Traboulsi et al., 2008). Todavia ainda não há estudos científicos que avaliam o potencial tóxico em modelos "in vivo" com Galleria mellonella, sendo assim, nossos dados são inéditos.

No ensaio "in vivo" realizado no presente estudo, as larvas de Galleria mellonella foram expostas ao óleo essencial de Melaleuca alternifolia, sendo 10 larvas expostas a $4 \mathrm{mg} / \mathrm{mL}$ do óleo essencial e 10 larvas expostas a $8 \mathrm{mg} / \mathrm{mL}$ do óleo essencial e comparadas ao controle (larvas que não foram expostas ao óleo essencial e nelas somente foi injetada água para observar se as mesmas morreriam com a picada). Todas as larvas tiveram taxa de sobrevivência de $100 \%$ comparadas ao controle.

\section{Conclusões}

Os resultados do ensaio de toxicidade "in vivo" não demonstram potencial tóxico do óleo essencial sobre a espécie de larvas testada nas concentrações avaliadas. Esses resultados criam perspectivas positivas sobre uma nova fonte de substâncias bioativas potencialmente seguras para aplicação clínica. Todavia, esses ensaios são preliminares necessitando ainda de muitos estudos com o óleo essencial de Melaleuca alternifolia.

FAEPEX/FUNCAMP

\section{Agradecimentos}

Astani A, Reichling J, Schnitzler P. Comparative study on the antiviral activity of selected monoterpenes derived from essential oils. Phytother Res. 2010; 24: 673-9.

Cechinel Filho V, Yunes RA. Estrategies for obtaining pharmacologically active compounds from medicinal plants: concepts about structural modification for improve the activity. Quím Nova. 1998 Feb;21(1):99-105.

Filoche SK, Soma K, Sissons CH. Antimicrobial effects of essential oils in combination with chlorhexidine digluconate. Oral Microbiol Immunol. 2005; 20: $221-5$

Oliveira FQ, Gobira B, Guimarães C, Batista J, Barreto M, Souza M. Plants species indicated in odontology. Rev Bras Farmacogn. 2007 Sep;17(3):466-76.

Santos EB, Dantas GS, Santos HB, Diniz MFFM, Sampaio FC. Etnobotanical studies of medicinal plants for oral conditions in the municipality of João Pessoa, Brazil. Rev Bras Farmacogn. 2009 Mar;19(1B):321-4.

Traboulsi RS, Mukherjee PK, Ghannouma MA. In vitro activity of inexpensive topical alternatives against Candida spp. isolated from the oral cavity of HIV infected patients. Int J Antimicrob Agents. 2008; 31:272-6.

Wynn, R.L.; Jabra-Rizk, M.A.; Meiller, T.F. Antifungal drugs and fungal resistance: the need for a new generation of drugs. Gen Dent, v.47, p. 352-5, 1999. 